\title{
How Households Adopt Sustainable Innovations? A Free Decision Enforced by Others
}

\author{
Ingo Kastner $(\mathbb{D})$ and Sebastian Bobeth \\ Otto-von-Guericke University Magdeburg, Institute of Psychology, Department of Environmental Psychology, \\ Universitätsplatz 2 Magdeburg 39106, Germany \\ Correspondence should be addressed to Ingo Kastner; ingo.kastner@ovgu.de
}

Received 20 March 2018; Accepted 17 July 2018; Published 2 August 2018

Academic Editor: Emin Açıkkalp

Copyright (C) 2018 Ingo Kastner and Sebastian Bobeth. This is an open access article distributed under the Creative Commons Attribution License, which permits unrestricted use, distribution, and reproduction in any medium, provided the original work is properly cited.

\begin{abstract}
Households play a crucial role in the transition of the energy system. They can make major contributions to sustainable development by adopting "green" innovations since such actions have a substantial impact on overall energy consumption. Theory suggests that innovations are first adopted by persons with specific dispositions, i.e., people with a high level of technical interest, relevant knowledge, and proenvironmental orientation. As an innovation spreads, early adopters yield social influences on others encouraging them to adopt, too. In theory, such effects should be found regardless of the nature of the innovation. We compared three green investments (residential insulation, solar thermal energy systems, and e-cars) at different diffusion stages in Germany. In three experiments, decision-makers in households were asked for their willingness to adopt the innovations; their dispositions and perceived social influences were measured in questionnaires. Social influences were found to affect all innovation adoptions while dispositions showed specific effects: technical interest was found to affect e-car and solar thermal energy adoptions; a proenvironmental value orientation only affected residential insulation. We conclude that it is worthwhile to shape policy measures to the innovation characteristics. However, social influences should always be taken in account.
\end{abstract}

\section{Introduction}

Over the last few years, there have been some advances in the worldwide energy transition process. In 2014, 13.7\% of the worldwide energy production was based on renewable sources-as compared to only $12.9 \%$ in 2000 [1]. The most promising developments have occurred in the field of electricity where $22.3 \%$ were produced from renewable energy sources (in 2014 [1]). Germany can serve as a leading example: in the last five years, German renewable electricity generation increased by over 10 percentage points and reached an overall share of $33.1 \%$ in 2017 [2]

The progress in other fields-such as heat and mobilityis substantially slower. Only approximately $5 \%$ of the worldwide heat generation is based on renewable energy sources [1] and efficiency measures reducing heat demand (e.g., building insulation) are taken slowly (see e.g., [3] for the situation in Germany). Additionally, the use of more energyefficient driving systems-such as e-mobility—is still low and spreading slowly. Substantial increases in e-mobility use have only taken place in a small number of countries. Norway, where $32 \%$ of the newly licensed vehicles are e-cars, is setting a positive example in this respect [4].

The exemplary developments in Germany and Norway have one thing in common: in both cases, hard policy measures have been implemented pushing the innovations to spread. In Germany, the EEG reallocation charge has been established in 2003. The charge is used to finance renewable energy extension in Germany. It is to be paid by all electricity consumers and charged on every kWh. In 2018, the charge reached an amount of $6.792 \mathrm{ct}$. per kWh [5]. In German households the EEG reallocation charge currently accounts for approximately $25 \%$ of the overall electricity costs (depending on the exact electricity tariff [6]). In Norway, e-car use is supported by substantial tax exemptions: when purchasing a car, Norwegians usually have to pay $25 \%$ VAT plus a registration tax depending on the car's weight, engine power, and environmental impact. For a middle-class car, for 
example, the registration tax can vary between $€ 5,000$ and $€$ 10,000. Since 1996, e-cars are exempted from the registration tax and since 2001 from VAT. Still, both taxes are charged for combustion engine cars. Additionally, e-car use is supported by providing free access to a number of toll roads, ferries, car parks, and bus lanes [7].

The success of these policy measures raises the question why they are not transferred to other countries and sectors (e.g., heat consumption). The main problem is that such measures pose a strong burden on end-users, namely, households. Charges on, for instance, heat energy, would imply substantial additional costs-especially as most energy in households is used for heat generation [8]. Consequently, such measures might lead to strong opposition (e.g., [9]). This might be the reason why other measures have been implemented in these sectors: most countries mainly rely on financial incentives fostering renewable generation and efficiency in the heat energy sector and to increase e-car use [10]. The outcomes of these approaches are widely negligible though (see e.g., $[3,11]$, for examples from Germany). Theory suggests that these financial incentives either are not strong enough or are insufficiently accompanied by marketing measures capturing the motives of potential investors [12]. Such motives can take various forms and only partly involve financial expectations (e.g., $[13,14])$.

The scope of this work is to identify crucial motives encouraging decision-makers to make (or omit) energyrelevant investments. We are focusing on household investments in the sectors heat and mobility for two reasons: first, both sectors are lagging back in the energy transition. Second, households are an important consumer group that is also strongly affected by policy measures. The situation in Germany will serve as an example where different measures have been implemented in both sectors at varying effectiveness. First, we will discuss how innovations are generally adopted taking a social science perspective. We will then present data from three choice experiments simulating households' energy-relevant decision-making in the fields of heat consumption and mobility. Exemplary, we will look into the drivers of residential building insulation, investments in solar thermal systems, and the purchase of e-cars for private use. The results will provide insights of how current policy measures should be changed in respect of investment motives and whether they should be adjusted for the different decision domains (e.g., residential insulation, e-car purchase).

\section{Background}

2.1. Energy-Relevant Decisions. Investments in e-cars, solar thermal energy systems, or residential insulation are all still relatively uncommon actions for German households (see $[3,11,17]$ for more information). In other words, all these investments qualify as innovations. Several models have been developed to explain how innovations are adopted and disseminated. One well-known theory illustrating societal transformation processes is the diffusion of innovation theory (DOI; [13]). The DOI describes how an innovation spreads (or fails to spread) through society over time. In this theory, "innovation" is broadly defined covering new technologies, procedures, ideas, etc.

Whether an innovation is adopted or not depends on how it is-subjectively-evaluated by the decision -makers. According to the DOI the decision-makers rate the following aspects:

(i) Relative advantage: Will the use of the innovation improve the current state?

(ii) Compatibility: Does the innovation fit the needs and the current system?

(iii) Complexity: Is it easy to use?

(iv) Trialability: Can it be tested before the adoption?

(v) Observability: Are there already visible positive effects for users of the innovation?

Rogers [13] notes that all these aspects interact and are rated as a whole by the decision-maker. Thus, negative ratings for some aspects can be compensated if others are rated positively. This underlines that policy-makers should not only rely on financial incentives. In fact, only the relative advantage might be changed by incentives while the other aspects are better addressed by other strategies, e.g., information campaigns. Furthermore, relative advantage ratings are not necessarily based on financial factors only [13]. They are therefore addressable by other policy measures as well.

Different groups have been identified adopting an innovation at different points of time during the dissemination process [13]. Innovators are the first group to adopt an innovation, followed by Early Adopters and the Early and the Late Majority; Laggards are the last group to make an adoption, if they ever do. The groups differ in certain characteristics. According to the DOI, early adopting groups include decision-makers with certain dispositions: they have a high technical interest and a high level of innovation-related knowledge. Such factors usually support early adoptions as these decision-makers rate an innovation as, for instance, less complex, more compatible, and/or more advantageous. When it comes to the adoption of "green innovations" (e.g., technologies having a positive impact on the natural environment), the proenvironmental orientation of the decisionmakers can be another relevant factor (e.g., [14, 18]). As compared to late adopters, early adopting groups are not very sensitive towards financial incentives [13]. This finding underlines again that it may not be worthwhile concentrating on incentives only, especially as long as an innovation has not been widespread yet.

According to the DOI, social dynamics play a key role for the diffusion of innovations [13]: persons who have decided to adopt an innovation or not can wield social influences over others who have not decided yet [19]. Therefore, social dynamics can either support or inhibit the diffusion of innovations. As an innovation spreads through society, social influences can be expected to increase.

The number of empirical studies investigating energyrelevant investment decisions is quite small-and only a fraction of these studies investigates DOI decision factors (see $[20,21]$ for recent reviews). The available data reveals a mixed 
picture: technical interest, innovation-related knowledge, and proenvironmental orientations were only found to be partly relevant for both decision domains and heat and mobility investments [20-24]. Social influences were even less relevant, especially for heat-related investments [20, 25]. Those study results may be biased. In most cases, they rely on selfreported data measuring investment motives retrospectively. Such measurements are vulnerable to biases as decisionmakers may not remember their investment motives correctly (e.g., [26]). In addition, people deny making decisions under social influences because they favor seeing themselves as independent decision-makers-especially in Western countries where most investigations were conducted [26-28]. Other measurement approaches-such as choice experiments or observations-are less vulnerable to these biases [26] and hence are more suitable for assessing the relevance of these factors reliably. Some studies support this assumption: social influences become more relevant in decision-making if they are measured in an experimental setting [29-31] or via observation [32,33]. We chose discrete choice experiments as such an alternative approach for our analyses as a more reliable measurement methodology.

2.2. Research Agenda. Our study focusses on three energyrelevant investments in German households: e-cars, solar thermal energy systems, and residential insulations. Those three investments are still relatively rare and thus innovative $[3,11,17]$. We expected all three investments to be influenced by the drivers derived from the DOI and empirical analyses listed above, i.e., decision-makers' disposition - namely, technical interest, investment-relevant knowledge, and proenvironmental orientation-and social influences.

Nevertheless, the three investments can be interpreted to differ in their innovation level. All investments have low diffusion rates in Germany, but there are still substantial differences between the domains: the rate of voluntarily insulated older residential buildings lies between 10 and $21 \%$ (depending on component; [3]), the diffusion rate of residential use of solar thermal energy systems is approximately $10 \%$ [17], and the share of e-cars is $0.1 \%$ [11]. Thus, e-car adoption can be interpreted as the most innovative investment, followed by solar thermal energy system installations and insulation measures. We expect the decisionmakers' disposition to be more relevant for more innovative investments: technical interest, investment-relevant knowledge, and proenvironmental orientation should be most important for e-car investments, followed by solar thermal energy investments and residential insulation. Social influences are expected to have a reverse impact; they should be more relevant for those innovations that have already spread further. They should be most relevant for residential insulation, followed by solar thermal energy systems and ecar investments.

\section{Materials and Methods}

We drew on data from three online studies carried out in Germany. In 2014, we investigated home owners' willingness to make investments in residential insulation (study I) and solar thermal energy systems (study II); in 2016, we surveyed the willingness of new car buyers (in household) to purchase an e-car (study III).

3.1. Samples. The target groups were chosen based on their (high) potential to find themselves in decision situations about innovative investments. In the domains of insulation (study I) and solar thermal energy (study II), we chose home owners living in owner-occupied single and two-family houses for five years or longer. We found this group suitable because (a) only the owners are in the position to make an investment decision for the house they live in and (b) people living in the house for a longer period of time are very likely to have already considered such investments. In the domain of e-mobility (study III), we targeted household members that have already been involved in purchasing a new car in the past and were planning to purchase a new car again within the next two years. Again, we made this selection to gather samples which can easily immerse themselves in the decision situation. Selecting new car buyers was important as e-cars are usually bought as new cars. The samples were recruited via external panel providers. Screening questions ensured that only adequate participants entered the studies.

As compared to adult household members in Germany (see Table 1 for an overview), our participants were slightly older in studies I and II and slightly younger in study III (see also Figure 1). These are typical findings for the subpopulations of home owners [15] and new car buyers [34]. In study III, there were notably more men than women (Figure 2). Again, this is a typical finding for new car buyers (66\% of new car buyers are male; [34]). Across all studies, our participants had a higher income than average adult household members (Figure 3) and lived in households with more members (Figure 4), which are typical characteristics for potential early adopter groups [13].

3.2. Measurements. Each study involved a questionnaire and a choice task. The questionnaires addressed the decisionmakers' dispositions (technical interest, proenvironmental orientation, and investment-relevant knowledge) and social influences, which served as independent variables. We measured technical interest with the self-concept innovation scale by Krömker and Dehmel [35]. The three items measured on a 5-point Likert scale were "I see myself as a person who generally enjoys possessing new technologies," "I see myself as a person who generally enjoys being up to date on technological developments," and "I see myself as a person who generally enjoys when technology works efficiently.” The scales' internal consistency was within acceptable limits throughout the three studies (see Table 2 and Figure 5 for details).

The measurement of investment-relevant knowledge differed throughout the studies. In studies I and II, we used a single item measured on a 6-point Likert scale: "How well do you feel generally informed about the topic of insulation [or, in study II, “...the topic of solar thermal energy"]?” In study III, we extended the measurement to three items on a 5-point Likert scale. First, the participants should indicate the degree of their knowledge (from "not distinctive" to "very distinctive"): "How would you rate your knowledge on e-cars? 


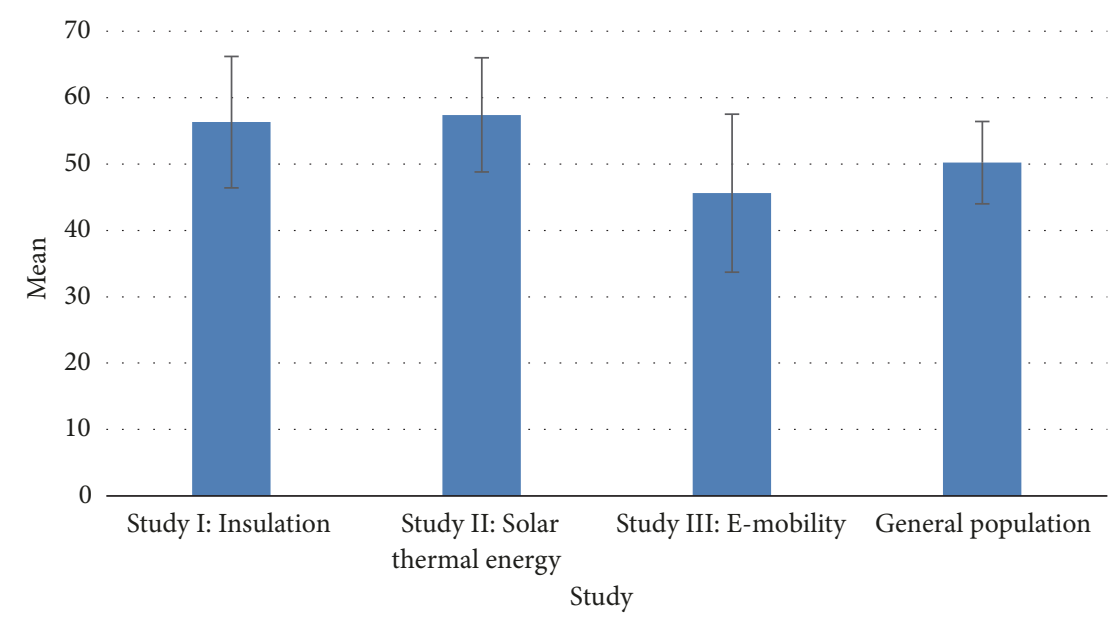

FIGURE 1: Age distributions (means and standard deviations) of the samples in comparison to the basic population of German adults.

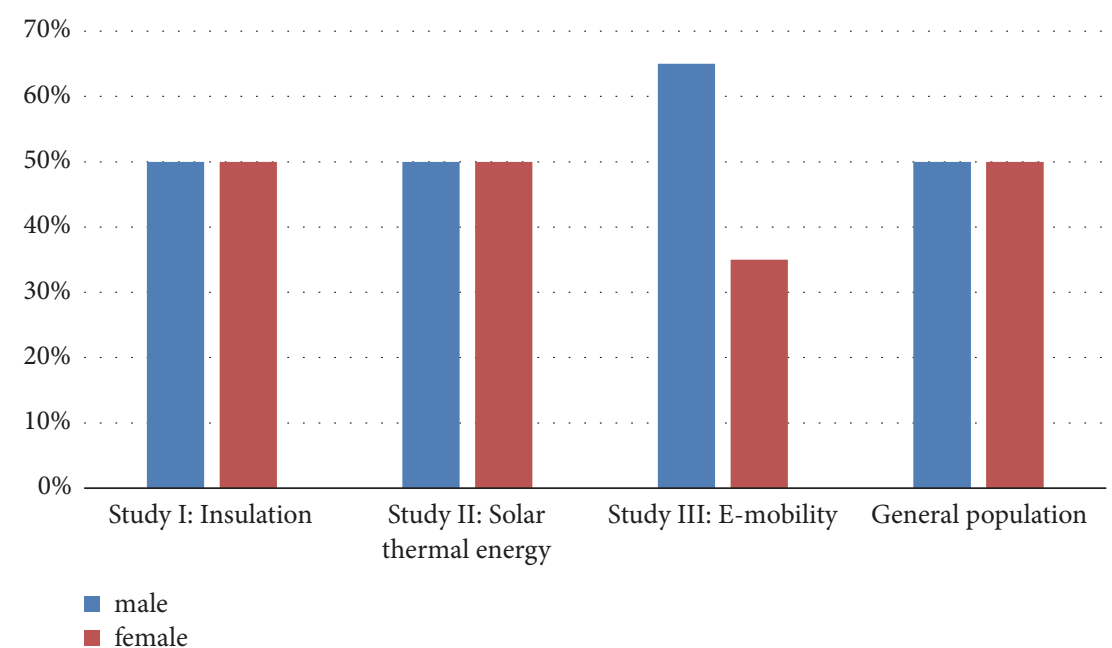

FIGURE 2: Gender distributions (in percent) of the samples in comparison to the basic population of German adults.

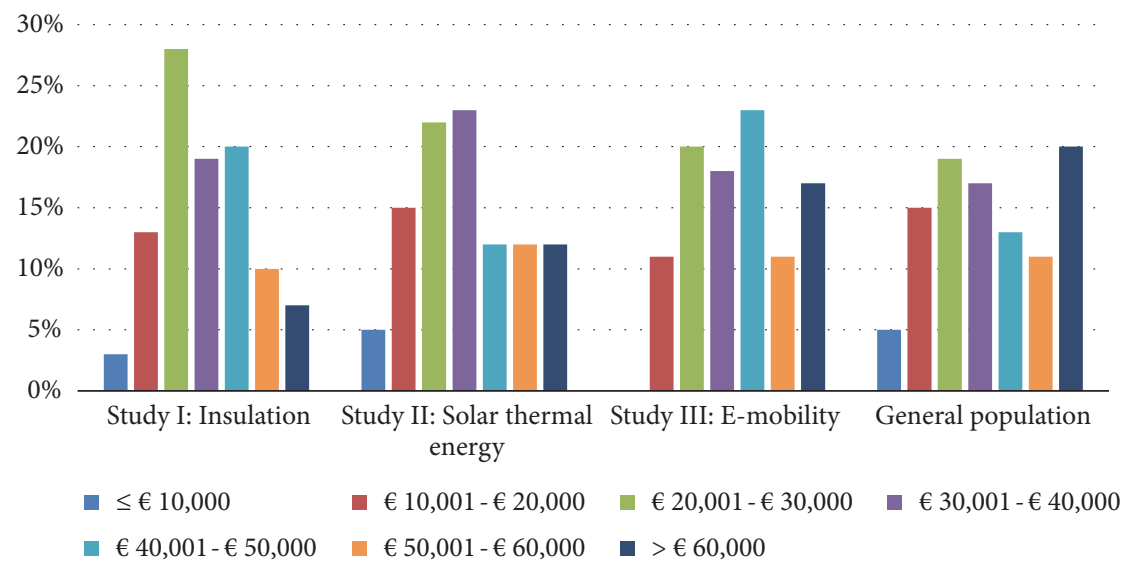

FIGURE 3: Income groups (in percent) of the samples in comparison to the basic population of German adults. The bars show the net income per year. 
TABLE 1: Sociodemographic data of the samples in comparison to the basic population of German adults.

\begin{tabular}{|c|c|c|c|c|}
\hline \multicolumn{5}{|c|}{ Study } \\
\hline & $\begin{array}{l}\text { Study I: Insulation } \\
\qquad(n=233)\end{array}$ & $\begin{array}{l}\text { Study II: Solar thermal energy } \\
\qquad(n=232)\end{array}$ & $\begin{array}{l}\text { Study III: E-mobility } \\
\qquad(n=227)\end{array}$ & General population \\
\hline Target group & \multicolumn{2}{|c|}{$\begin{array}{l}\text { Home owners living in owner-occupied single and two-family } \\
\text { houses } \geq 5 \text { years }\end{array}$} & $\begin{array}{l}\text { Households considering to } \\
\text { buy a new car }\end{array}$ & Adults in Germany \\
\hline \multicolumn{5}{|l|}{ Age } \\
\hline M & 56.3 & 57.4 & 45.6 & 50.2 \\
\hline SD & 9.9 & 8.6 & 11.9 & 6.2 \\
\hline \multicolumn{5}{|l|}{ Gender } \\
\hline male & $50 \%$ & $50 \%$ & $65 \%$ & $50 \%$ \\
\hline female & $50 \%$ & $50 \%$ & $35 \%$ & $50 \%$ \\
\hline \multicolumn{5}{|l|}{$\begin{array}{l}\text { Net household } \\
\text { income per year } \\
{[€]}\end{array}$} \\
\hline$\leq 10.000$ & $3 \%$ & $5 \%$ & $0 \%$ & $5 \%$ \\
\hline $10.001-20.000$ & $13 \%$ & $15 \%$ & $11 \%$ & $15 \%$ \\
\hline $20.001-30.000$ & $28 \%$ & $22 \%$ & $20 \%$ & $19 \%$ \\
\hline $30.001-40.000$ & $19 \%$ & $23 \%$ & $18 \%$ & $17 \%$ \\
\hline $40.001-50.000$ & $20 \%$ & $12 \%$ & $23 \%$ & $13 \%$ \\
\hline \multirow[t]{2}{*}{$50.001-60.000$} & $10 \%$ & $12 \%$ & $11 \%$ & $11 \%$ \\
\hline & $7 \%$ & $12 \%$ & $17 \%$ & $20 \%$ \\
\hline \multicolumn{5}{|l|}{$\begin{array}{l}\text { No. of } \\
\text { household } \\
\text { members }\end{array}$} \\
\hline M & 2.6 & 2.6 & 2.7 & 2.0 \\
\hline SD & 1.0 & 1.1 & 1.2 & 1.1 \\
\hline
\end{tabular}

Note. Data for the German population was obtained from Destatis $[15,16]$.

$\mathrm{n}=$ sample size as in number of participants, $\mathrm{M}=$ mean value of given variable in the sample (measured as central tendency of distribution), and $\mathrm{SD}=$ standard deviation of values of given variable from calculated mean in the sample.

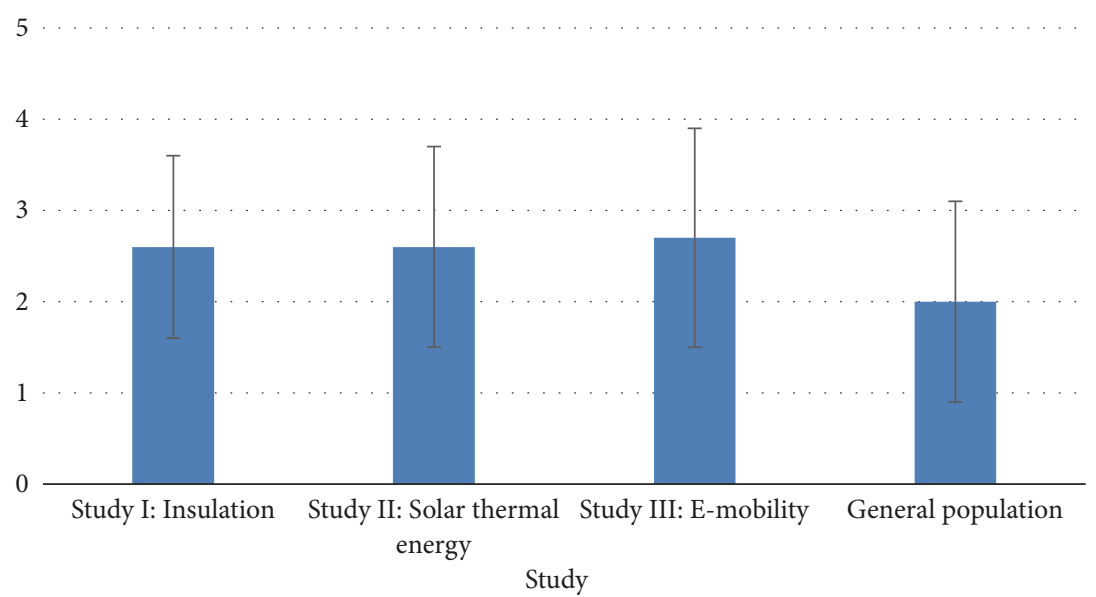

FIGURE 4: Number of household members (means and standard deviations) of the samples in comparison to the basic population of German households.

My knowledge is..." Then, they should indicate to which degree the following statements were accurate: "I know advantages and disadvantages of electric cars" and "I know enough to be able to compare electric cars with conventional cars." The internal consistency of the 3-item scale was good.
We measured proenvironmental orientation with three items of the self-transcendence scale from Stern, Dietz, and Guagnano's [36] value inventory which is based on the work of Schwartz [37]. The scale covers a person's eco-social value orientation. Participants indicated the importance of the 


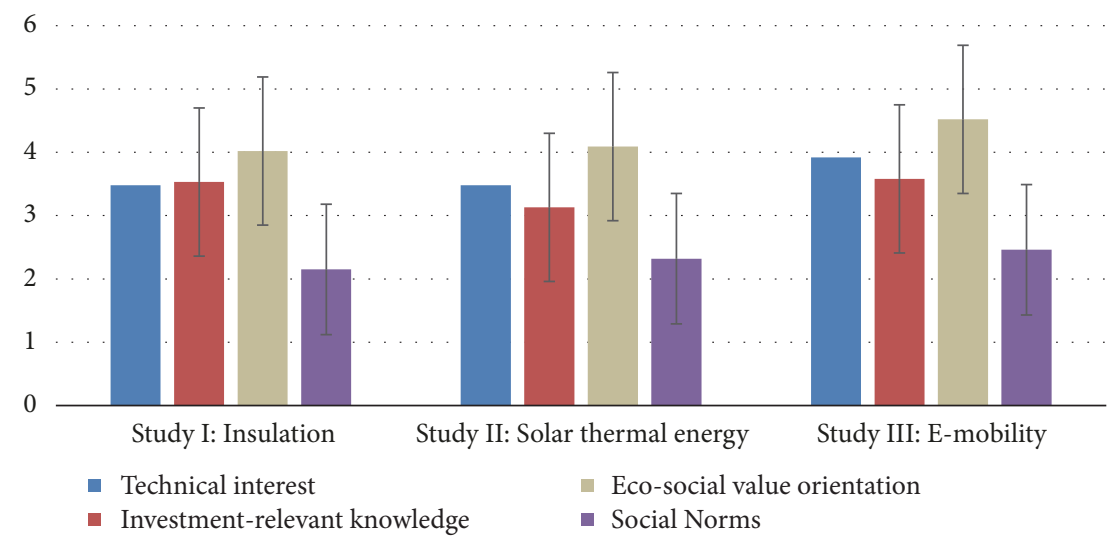

FIGURE 5: Descriptive data (means and standard deviations) of the independent variables and scales measured within the studies. Most items were measured on a 6-point Likert scale. In studies I and II, investment-relevant knowledge was measured on a 5-point Likert scale. The items were standardized for further analyses.

TABLE 2: Overview of independent variables.

\begin{tabular}{|c|c|c|c|}
\hline & $\begin{array}{l}\text { Study I: Insulation } \\
\qquad(n=233)\end{array}$ & $\begin{array}{l}\text { Study II: Solar thermal energy } \\
\qquad(n=232)\end{array}$ & $\begin{array}{l}\text { Study III: E-mobility } \\
\qquad(n=227) \\
\end{array}$ \\
\hline \multicolumn{4}{|l|}{ Technical interest } \\
\hline M & 3.48 & 3.48 & 3.92 \\
\hline $\mathrm{SD}$ & .78 & .77 & .73 \\
\hline Cronbach's $\alpha$ & .77 & .77 & .72 \\
\hline \multicolumn{4}{|c|}{ Investment-relevant knowledge } \\
\hline M & 3.53 & 3.13 & 3.58 \\
\hline $\mathrm{SD}$ & .85 & .89 & .80 \\
\hline Cronbach's $\alpha$ & N/A & $\mathrm{N} / \mathrm{A}$ & .79 \\
\hline \multicolumn{4}{|c|}{ Eco-social value orientation } \\
\hline M & 4.02 & 4.09 & 4.52 \\
\hline SD & .56 & .58 & .63 \\
\hline Cronbach's $\alpha$ & .62 & .65 & .79 \\
\hline \multicolumn{4}{|l|}{ Social norms } \\
\hline M & 2.15 & 2.32 & 2.46 \\
\hline $\mathrm{SD}$ & 1.03 & 1.17 & 1.17 \\
\hline Cronbach's $\alpha$ & N/A & $\mathrm{N} / \mathrm{A}$ & .85 \\
\hline
\end{tabular}

Note. Most items were measured on a 6-point Likert scale. In studies I and II, investment-relevant knowledge was measured on a 5-point Likert scale. The items were standardized for further analyses.

Cronbach's $\alpha$ is not available for investment-relevant knowledge and social norms in studies I and II. They were measured with single items in these studies. $\mathrm{n}=$ sample size as in number of participants, $\mathrm{M}=$ mean value of given variable in the sample (measured as central tendency of distribution), $\mathrm{SD}=$ standard deviation of values of given variable from calculated mean in the sample, and Cronbach's $\alpha=$ reliability estimate for internal consistency of used scales.

following aspects in their life on a 5-point Likert scale: "Protecting the environment, preserving nature," "A world at piece (free of war and conflict)," and "Social Justice (correcting injustice, care for the weak)." Again, the internal consistency was within acceptable limits throughout the studies.

Social influences were measured with the social norms scale by Ajzen ([38] originally referred to as "subjective norms"). The measurement assessed the perceived behavioral expectations of important people from a person's social environment. We included one social norm item in studies I and II and three items in study III, each measured on a 5point Likert scale. In studies I and II, the item asked whether the participants agreed to the statement "People who are important to me think that I should undertake insulation measures [“... should install solar thermal energy"].” In study III, the items were "People who are important to me expect me to choose an electric car when purchasing a car," "People who are important to me insinuate that I should consider electric cars when purchasing a car," and "People who are important to me support me when I buy an electric car." The internal consistency of the 3-item scale was good. Our participants answered the questionnaire in German language. The scales eco-social value orientation and Social norms had originally been developed in English language and 
were translated into German for our studies. The scales or, respectively, items technical interest and investment-relevant knowledge had been developed in German language and were translated into English for this paper.

The participants' decisions whether or not to make an investment formed the dependent variable. We measured investment willingness in the fields of insulation, solar thermal energy, and e-mobility in three discrete choice experiments. Discrete choice experiments are a common measure to investigate peoples' choices between different investment alternatives in a realistic decision situation. Within the experiments, alternatives vary in several attributes that are expected to affect the decision (e.g., price, technical issues, or appearance). Participants are usually asked to make a number of repeated choices allowing a better estimation of each attribute's decision relevance [39]. Mixed logit modeling is the suitable approach to investigate the influence of different kinds of variables on participants' decisions in discrete choice experiments (see, e.g., [40] for more information).

All experiments involved several choice sets (17 choices in studies I and II, twelve choices in study III) with a varying number of context factors. The factors were based on realworld parameters in order to create a realistic decision situation. We particularly varied financial aspects (e.g., investment costs), technological aspects (e.g., charging infrastructure), and legal aspects (e.g., guarantee extents). We chose this approach to investigate whether the influence of the independent variables was stable under varying conditions (further details of the choice task design have been reported elsewhere. For studies I and II, see [31]; for study III, see [30]). Additionally, choice experiments investigating investment decisions were found to be less vulnerable to biases (e.g., hindsight bias, social desirability) than, for instance, questionnaire data. [20].

The participants' willingness to make investments in the choice tasks was relatively high. Overall, investments were made in $74 \%$ of all choice situations. The figure was higher in studies I and II (79\%) than in study III (59\%). It is possible that the skepticism towards e-cars was generally higher as the diffusion of the innovation was on a lower level.

3.3. Data Analysis. Our data were evaluated in mixed logit models. Mixed logit modeling provides a suitable approach to analyze data from discrete choice experiments. (see, e.g., [40] for more information). We built three mixed logit models covering household investment decisions in residential insulation (model I), solar thermal energy systems (model II), and e-cars (model III). We used the R package mlogit [41] and followed Croissant's [42] guidelines on its application.

Most analyses of discrete choice data focus on the influence of context factors [29, 30, 43-45]. In our models, we investigated the effects of dispositions (technical interest, investment-relevant knowledge, and eco-social value orientation) and social influences (independent variables) on the investment decisions (dependent variable). All independent variables entered the models as individual specific variables (for more details on the mlogit procedure and the statistical reasoning behind it, see [42]). The formulas also took into account the panel structure of our data and assumed normal distribution of the entered variables. Pseudo random sequences were used in the model estimation process. As we measured investment-relevant knowledge on a different Likert scale in studies I and II, we standardized all independent variables.

\section{Results and Discussion}

For all three investment decisions-residential insulation, solar thermal energy systems, and e-cars-we calculated the decision relevance of technical interest, investment-relevant knowledge, eco-social value orientation, and social norms. All statistically significant effects reported in the following are positive; i.e., they encourage (and not undermine) an investment decision.

Eco-social value orientation and social norms entered model I (residential insulation) significantly (see Table 3 and Figure 6); no significant effects were found for technical interest and investment-relevant knowledge. In model II (solar thermal energy), significant effects were found for technical interest, investment-relevant knowledge, and social norms while no significant effect was found for eco-social value orientation. In model III (e-cars), significant effects were found for technical interest, eco-social value orientations, and social norms; no significant effect was found for investmentrelevant knowledge.

These findings are not in line with our initial expectation that all factors we investigated should affect all innovative investments to some degree. The relevance of decisionmakers' dispositions (technical interest, investment-relevant knowledge, and eco-social value orientation) varied between the investment domains; no disposition affected all investments. However, social norms had a strong influence on all investments.

Additionally, we only found some support for our assumption that factor relevance may change during the diffusion process. We expected that all decision-makers' dispositions (technical interest, investment-relevant knowledge, and eco-social value orientation) would be more important when the dissemination of an innovation was low. Thus, the strongest effects were expected for e-cars followed by solar thermal energy investments and residential insulation. An inverse pattern had been expected for social norms as social influences might increase the more an innovation spreads. These assumptions were partly met for technical interest and eco-social value orientation. Probably, factor relevance not only depends on the dissemination degree but also on the very nature of an investment. In the following, the results for each factor will be discussed in-depth.

Technical interest had a significant influence on e-car investments and solar thermal energy investments with a stronger effect for e-cars. For residential insulation, no significant effects were found. This pattern basically supports the assumption that the influence of the decision-makers' dispositions decreases as an innovation spreads. Technical interest may also be more important for e-cars as they allow the users to interact with an innovative technology intensively and on an ongoing basis. A permanent interaction is also possible for solar thermal energy systems, e.g., by 
TABle 3: Estimated Choice Models.

\begin{tabular}{|c|c|c|c|}
\hline & $\begin{array}{l}\text { Model I: } \\
\text { Insulation }\end{array}$ & $\begin{array}{l}\text { Model II: } \\
\text { Solar thermal } \\
\text { energy }\end{array}$ & $\begin{array}{l}\text { Model III } \\
\text { E-mobility }\end{array}$ \\
\hline \multicolumn{4}{|c|}{ Technical interest } \\
\hline Estimate & -.05 & .17 & .68 \\
\hline Std. Error & .24 & .06 & .12 \\
\hline $\mathrm{t}$ & -.90 & $2.68^{*}$ & $5.47^{* *}$ \\
\hline \multicolumn{4}{|c|}{ Investment-relevant knowledge } \\
\hline Estimate & -.16 & .30 & -.08 \\
\hline Std. Error & .10 & .15 & .07 \\
\hline $\mathrm{t}$ & -1.65 & 1.95 & -1.20 \\
\hline \multicolumn{4}{|c|}{ Eco-social value orientation } \\
\hline Estimate & .23 & .09 & -.13 \\
\hline Std. Error & .08 & .08 & .14 \\
\hline $\mathrm{t}$ & $2.77^{*}$ & 1.11 & -1.00 \\
\hline \multicolumn{4}{|l|}{ Social norms } \\
\hline Estimate & .29 & .31 & .74 \\
\hline Std. Error & .05 & .05 & .08 \\
\hline $\mathrm{t}$ & $6.22^{* *}$ & $6.40^{* *}$ & $8.85^{* *}$ \\
\hline $\mathrm{n}$ & 233 & 232 & 227 \\
\hline df & 3946 & 3929 & 1329 \\
\hline Log Likelihood & -5439.2 & -5369.4 & -1597.1 \\
\hline
\end{tabular}

Note. ${ }^{*} p<0.05,{ }^{* *} p<.001$.

$\mathrm{n}=$ sample size as in number of participants, Estimate = value calculated for increasing investment probability if given variable value increases accordingly, Std. Error $=$ standardized error estimate for standard deviation, $\mathrm{t}=\mathrm{t}$ value in two-sided test in single group, and $\mathrm{df}=\mathrm{degrees}$ of freedom.

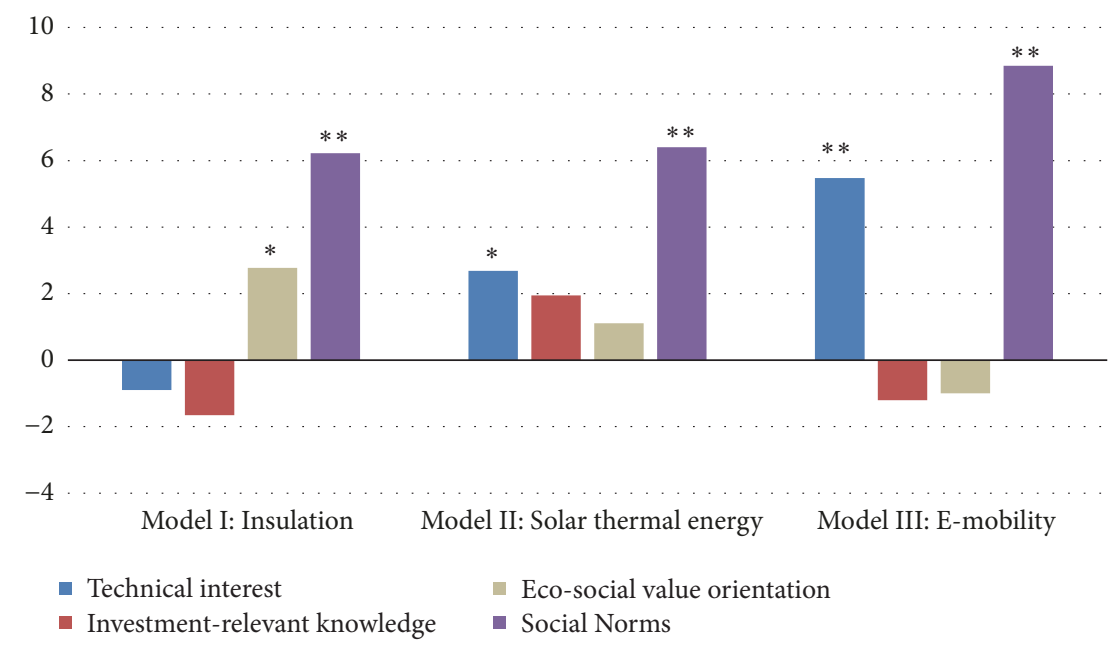

Figure 6: Results from the Estimated Choice Models. The bars show the t-values for each independent variable. The asterisks indicate which variables entered the models significantly $\left({ }^{*} p<0.05,{ }^{* *} p<.001\right)$.

use of the control panels, but the interaction level is lower. Insulation measures do not allow for user interactions once the installation is completed.

The findings concerning investment-relevant knowledge are somewhat surprising as we expected the same pattern to occur as for technical interest. However, investmentrelevant knowledge was only found to influence solar thermal energy investment but not the other investment domains.
Probably, the importance of investment-relevant knowledge is somewhat overestimated as compared to other factors. The feeling of having a certain level of information may be an important precondition for some decision-makers, but this may not be enough to finally decide (see also [46]). One may also note that our approach to measure investment-relevant knowledge via self-reports may not be the best manner to evaluate the true level of information. Former studies indicate 
that energy-relevant investment decisions are rather led by subjective (i.e., self-assessed) knowledge than by verifiable expert knowledge measured in knowledge tests [20].

Another surprising finding is that the eco-social value orientation affected e-car and residential insulation investments but not the investments in solar thermal energy systems. Again, these effects may be grounded in differences between the investment domains. One important difference may lie in the initial investment costs that are-on average-highest for insulation measures, followed by ecars and solar thermal energy systems. In our experiments, investment costs in the choice scenarios were based on realistic average values: the costs ranged from $€ 10,000$ to 30,000 for insulation measures, were set to $€ 25,000$ for e-cars, and ranged from $€ 5,000$ to $€ 10,000$ for solar thermal energy systems (the values were calculated from [47-50]). The higher investment costs for building insulation and e-cars may be a strong barrier for many decision-makers. This problem might also be aggravated by the perceived profitability: all investments have a fair chance to pay off but most decisionmakers do not calculate the payback period correctly. For instance, decision-makers frequently neglect energy price developments, interest, and inflation rate. Hence, they often do not expect investments with high initial costs paying off at all [51]. Research on proenvironmental behavior suggests that persons with a strong proenvironmental orientation are more likely to overcome such barriers ("behavioral costs"; e.g., [18]). Thus, strong eco-social values may be more relevant for high cost investments.

Finally, we found social norms to affect all investment decisions to a very high degree. Across all three models, their impact was the highest of all included factors. These findings also somewhat contradict our assumption that their influence increases as an innovation spreads. In fact, social norms in the decision-makers' peer group seem to be highly relevant even at early stages of dissemination. This does not necessarily mean that they do not become even more important over time but such developments may be hard to detect due to ceiling effects (e.g., [26]).

\section{Conclusions}

Our study shows that households' adoption of innovative technologies depends on several factors. Different investment motives were found to only affect certain types of investments. Social influences were found to be relevant for all investigated investment domains. These findings indicate that policy measures should be tailored accordingly. Some approaches for the design of such measures will be proposed in the following.

We found that investments implicating an intensive interaction with new technologies are rather taken by decisionmakers with a high technical interest. This finding may be somewhat unsurprising-but it is also highly relevant for the design of policy measures. Persons with a high technical interest are a key group to initiate the dissemination process [13]. Thus, policy measures and products should be designed to reach them effectively. Especially in the early stages of an innovation, information strategies should focus on technical aspects and interaction possibilities. They could involve mass media campaigns or, for instance, events where interested persons can test and observe the innovations (e.g., driving e-cars, showrooms for renewable energy systems). In addition, products should be designed to allow a high level of interaction and provide attractive user interfaces.

We also found that decision-makers with a strong ecosocial value orientation were more likely to make investments in high-priced innovations, namely, e-cars and residential insulation, while the value orientation did not affect the less costly investments in solar thermal energy systems. We assume that strong eco-social values encourage decisionmakers to overcome strong barriers (e.g., costs) for an investment (e.g., $[18,52])$. The role of eco-social value orientations should also be considered in the design of policy measures. Focusing on these dispositions may be most worthwhile for innovations not allowing much interaction with new technologies, such as residential insulation measures. Again, information strategies may be one important intervention approach. Mass media campaigns could be designed stressing the substantial environmental benefits resulting from the investments. Decision-makers with strong eco-social values could be encouraged to adopt the innovations. Additionally, measures could be taken to increase eco-social value orientations themselves, e.g., via educational programs (e.g., [53]). Such approaches may be somewhat demanding and not all of them will lead to immediate effects. However, if proenvironmental dispositions are effectively supported, stable and overreaching outcomes can be expected: strong proenvironmental dispositions can make people act ecofriendly across different contexts (spillover; e.g., [54]). Such stability may be an important step to overcome the negative byeffects (rebound) of several conventional (e.g., incentive focused) policy measures (e.g., [52]). In other words, large-scale information campaigns may be demanding and costly at first-but they are most likely paying off in the long run (see also [55]).

Our most important finding lies in the substantial relevance of social influences: unlike the other factors we investigated, social influences were found to affect all energyrelevant investment domains we investigated to a very high degree. The perceived expectations of significant others are apparently highly relevant for the adoption of any innovation and thus should always be integrated in policy measures. To achieve this, several approaches can be envisaged: information strategies could be designed to send normative messages encouraging decision-makers to act in the same way as their peer group (e.g., "Two thirds of the homeowners in your neighborhood made investments in renewable energies in the last three years." See [56]). Additionally, the messages could be sent by social models, e.g., in mass media campaigns (e.g., $[57,58])$. It is important, though, that decision-makers find such models trustworthy and that they can - at best-identify themselves with the models. Block leaders are specific social models allowing for such identification in particular (e.g., $[57,58])$ : they are persons from the target group (e.g., home owners) who have already undertaken the action in question (e.g., they adapted a "green" innovation). As they already went through the decision process, they understand the situation and they can offer relevant information and thus 
wield social influences. Contact between block leaders and other decision-makers could, for instance, be established by providing low-threshold services (e.g., information events) where the groups could meet and exchange information. This should happen on a local level to grant proximity between block leaders and the target group. Identifying and supporting block leaders and organizing such services might require some effort for policy-makers-but again this is likely to pay off. Similar to proenvironmental dispositions, social influences can be expected to support proenvironmental actions in different domains and thus help to avoid negative byeffects of other policy measures.

Our work shows that policy-makers should not only rely on hard measures (e.g., compulsory charges or financial incentives) to promote the energy transition. In fact, focusing on such hard measures can lead to social problems, limited outcomes, and negative byeffects. We claim that these measures should be at least complemented with elaborate soft measures, such as information strategies considering investment motives and social dynamics and supporting proenvironmental orientations. Sophisticated approaches (e.g., educational measures, block leaders) may be demanding but their effects can be expected to be comprehensive and permanent. Of course hard measures should not be abandoned especially as financial support may be a necessary precondition for several actions. But only holistic strategies involving hard and soft measures can be really effective on the path towards a sustainable energy transition.

\section{Data Availability}

The data used to support the findings of this study are available from the corresponding author upon request.

\section{Conflicts of Interest}

The authors declare that there are no conflicts of interest.

\section{Acknowledgments}

The authors would like to thank all those who scientifically or practically supported their project. Special thanks also go to their colleagues, Professor Dr. Ellen Matthies and Karen Krause from the Otto-von-Guericke-University Magdeburg, who gave them valuable input during the preparation of this paper. This study was conducted as part of the KOPERNIKUS Project ENavi (system integration) funded by the German Federal Ministry of Education and Research.

\section{References}

[1] European Union (EU), EU Energy in Figures - Statistical Pocketbook, 2016.

[2] Arbeitsgemeinschaft Energiebilanzen e.V. (AGEB), Strommix, 2018.

[3] Institut Wohnen und Umwelt (IWU) \& Bremer Energie Institut (BEI), Datenbasis Gebäudebestand - Datenerhebung zur energetischen Qualität und zu den Modernisierungstrends im deutschen Wohngebäudebestand, 2010.
[4] EV Volumes, Global Plug-in Sales for 2017-Q4 and the Full Year (prelim.), 2018.

[5] Bundesnetzagentur, EEG-Umlage, Nomos, 2018.

[6] Statistisches Bundesamt (Destatis), Verbraucherpreisindizes, 2018.

[7] E. Figenbaum and M. Kolbenstvedt, Electromobility in Norwayexperiences and opportunities with Electric Vehicles, 2013.

[8] Arbeitsgemeinschaft Energiebilanzen e.V. (AGEB), Anwendungsbilanzen, 2018.

[9] S. Bamberg, S. Fujii, M. Friman, and T. Gärling, "Behaviour theory and soft transport policy measures," Transport Policy, vol. 18, no. 1, pp. 228-235, 2011.

[10] International Energy Agency (IEA), "Adressing Climate Change," Policies and Measures Databases, 2017.

[11] Kraftfahrt-Bundesamt KBA, Jahresbilanz des Fahrzeugbestandes am 1. Januar, 2018.

[12] G. T. Gardner and P. C. Stern, Environmental problems and human behavior, Pearson, Boston, MA, 2002.

[13] E. M. Rogers, Diffusion of innovations, Free press, 2010.

[14] P. C. Stern, "Toward a coherent theory of environmentally significant behavior," Journal of Social Issues, vol. 56, no. 3, pp. 407-424, 2000.

[15] Statistisches Bundesamt (Destatis), Wirtschaftsrechnungen Einkommens- und Verbrauchsstichprobe: Einnahmen und Ausgaben privater Haushalte, 2015.

[16] Statistisches Bundesamt (Destatis), Bevölkerung und Erwerbst $\Sigma$ tigkeit Haushalte und Familien: Ergebnisse des Mikrozensus, 2017.

[17] R. Corradini, Regional differenzierte Solarthermie-Potenziale für Gebäude mit einer Wohneinheit. (PhD Dissertation [Ph.D. thesis], Ruhr-Universität Bochum, Bochum, 2013.

[18] F. G. Kaiser, K. Byrka, and T. Hartig, "Reviving campbell's paradigm for attitude research," Personality and Social Psychology Review, vol. 14, no. 4, pp. 351-367, 2010.

[19] C. A. Klöckner, The psychology of pro-environmental communication: beyond standard information strategies, Springer, 2015.

[20] I. Kastner and P. C. Stern, "Examining the decision-making processes behind household energy investments: A review," Energy Research \& Social Science, vol. 10, pp. 72-89, 2015.

[21] Z. Rezvani, J. Jansson, and J. Bodin, "Advances in consumer electric vehicle adoption research: A review and research agenda," Transportation Research Part D: Transport and Environment, vol. 34, pp. 122-136, 2015.

[22] C. Barbarossa, S. C. Beckmann, P. De Pelsmacker, I. Moons, and W. Gwozdz, "A self-identity based model of electric car adoption intention: Across-cultural comparative study," Journal of Environmental Psychology, vol. 42, pp. 149-160, 2015.

[23] M. Bockarjova and L. Steg, "Can Protection Motivation Theory predict pro-environmental behavior? Explaining the adoption of electric vehicles in the Netherlands," Global Environmental Change, vol. 28, no. 1, pp. 276-288, 2014.

[24] O. Egbue, S. Long, and V. A. Samaranayake, "Mass deployment of sustainable transportation: evaluation of factors that influence electric vehicle adoption," Clean Technologies and Environmental Policy, vol. 19, no. 7, pp. 1927-1939, 2017.

[25] J. Kim, S. Rasouli, and H. Timmermans, "Expanding scope of hybrid choice models allowing for mixture of social influences and latent attitudes. Application to intended purchase of electric cars," Transportation Research Part A: Policy and Practice, vol. 69, pp. 71-85, 2014. 
[26] J. Bortz and N. Döring, "Forschungsmethoden und Evaluation: für Human-und Sozialwissenschaftler," in Research Methods and Evaluation: for Humanities and Social Sciences, Springer, Heidelberg, 2006.

[27] G. Hofstede, National Culture, 2017, https://geert-hofstede.com/ national-culture.html.

[28] G. Hofstede, G. J. Hofstede, and M. Minkov, Cultures and organizations: Software of the mind. Revised and expanded, McGraw-Hill, New York, NY, USA, 3 edition, 2010.

[29] M. Achtnicht and R. Madlener, "Factors influencing German house owners' preferences on energy retrofits," Energy Policy, vol. 68, pp. 254-263, 2014.

[30] S. Bobeth and E. Matthies, "New opportunities for electric car adoption: the case of range myths, new forms of subsidies, and social norms," Energy Efficiency, 2017.

[31] I. Kastner and E. Matthies, "Investments in renewable energies by German households: A matter of economics, social influences and ecological concern?" Research \& Social Science, vol. 17, pp. 1-9, 2016.

[32] B. Bollinger and K. Gillingham, "Peer effects in the diffusion of solar photovoltaic panels," Marketing Science, vol. 31, no. 6, pp. 900-912, 2012.

[33] M. Graziano and K. Gillingham, "Spatial patterns of solar photovoltaic system adoption: The influence of neighbors and the built environment," Journal of Economic Geography, vol. 15, no. 4, pp. 815-839, 2015.

[34] Deutsche Automobil Treuhand (DAT), DAT Report, 2016.

[35] D. Krömker and C. Dehmel, Einflussgrößen auf das Stromsparen im Haushalt aus psychologischer Perspektive, 2010.

[36] P. C. Stern, T. Dietz, and G. A. Guagnano, "A brief inventory of values," Educational and Psychological Measurement, vol. 58, no. 6, pp. 984-1001, 1998.

[37] S. H. Schwartz, "Universals in the content and structure of values: theoretical advances and empirical tests in 20 countries," Advances in Experimental Social Psychology, vol. 25, pp. 1-65, 1992.

[38] I. Ajzen, "The theory of planned behavior," Organizational Behavior and Human Decision Processes, vol. 50, no. 2, pp. 179-211, 1991.

[39] B. K. Orme, Getting started with conjoint analysis, Research Publishers LLC, Madison, WI, 2006.

[40] K. E. Train, Discrete Choice Methods with Simulation, Cambridge University Press, Cambridge, UK, 2003.

[41] Y. Croissant, Package 'mlogit', 2015, Package mlogit, Retrieved from.

[42] Y. Croissant, "Estimation of multinomial logit models," in $R$ : The mlogit Packages, 2012.

[43] A. Alberini, S. Banfi, and C. Ramseier, "Energy efficiency investments in the home: Swiss homeowners and expectations about future energy prices," Energy, vol. 34, no. 1, pp. 49-86, 2011.

[44] C. C. Michelsen and R. Madlener, "Homeowners' preferences for adopting innovative residential heating systems: A discrete choice analysis for Germany," Energy Economics, vol. 34, no. 5, pp. 1271-1283, 2011.

[45] M. Sadler, Home energy preferences policy: Applying stated choice modeling to a hybrid energy economy model, Simon Fraser University, 2003.

[46] S. Bamberg and G. Möser, "Twenty years after Hines, Hungerford, and Tomera: A new meta-analysis of psycho-social determinants of pro-environmental behaviour," Journal of Environmental Psychology, vol. 27, no. 1, pp. 14-25, 2007.
[47] ADAC, Wie rentabel sind Elektroautos?, 2016.

[48] Bausparkasse Schwäbisch Hall, Renovierungskosten berechnen, 2015.

[49] B. u. S. B. Bundesministerium für Verkehr, CO2 Gebäudereport, Berlin, 2007, vier C print + mediafabrik.

[50] Deutsche Energie-Agentur [DENA], "Modernisierungsratgeber Energie - Kosten sparen, Wohnwert steigern, Umwelt schonen," Schöneweide, 2010.

[51] T. Albrecht and S. Zundel, Gefühlte Wirtschaftlichkeit - Wie Eigenheimbesitzer energetische Sanierungsmaßnahmen ökonomisch beurteilen, 2010.

[52] S. Otto, F. G. Kaiser, and O. Arnold, "The critical challenge of climate change for psychology: Preventing rebound and promoting more individual irrationality," European Psychologist, vol. 19, no. 2, pp. 96-106, 2014.

[53] S. Otto and P. Pensini, "Nature-based environmental education of children: Environmental knowledge and connectedness to nature, together, are related to ecological behaviour," Global Environmental Change, vol. 47, pp. 88-94, 2017.

[54] J. Thøgersen and T. Crompton, "Simple and painless? The limitations of spillover in environmental campaigning," Journal of Consumer Policy, vol. 32, no. 2, pp. 141-163, 2009 (Chinese).

[55] J. Steinhorst and C. A. Klöckner, "Effects of Monetary Versus Environmental Information Framing: Implications for LongTerm Pro-Environmental Behavior and Intrinsic Motivation," in Environment and Behavior, 2017.

[56] R. B. Cialdini, "Basic social influence is underestimated," Psychological Inquiry, vol. 16, no. 4, pp. 158-161, 2005.

[57] H.-J. Mosler and R. Tobias, "Umweltpsychologische Interventionsformen neu gedacht: Rethinking forms of environmental psychology interventions," Umweltpsychologie, vol. 11, no. 1, pp. 35-54, 2007.

[58] R. Osbaldiston and J. P. Schott, "Environmental Sustainability and Behavioral Science: Meta-Analysis of Proenvironmental Behavior Experiments," in Environment and Behavior, vol. 44, 299, 257, 2012. 

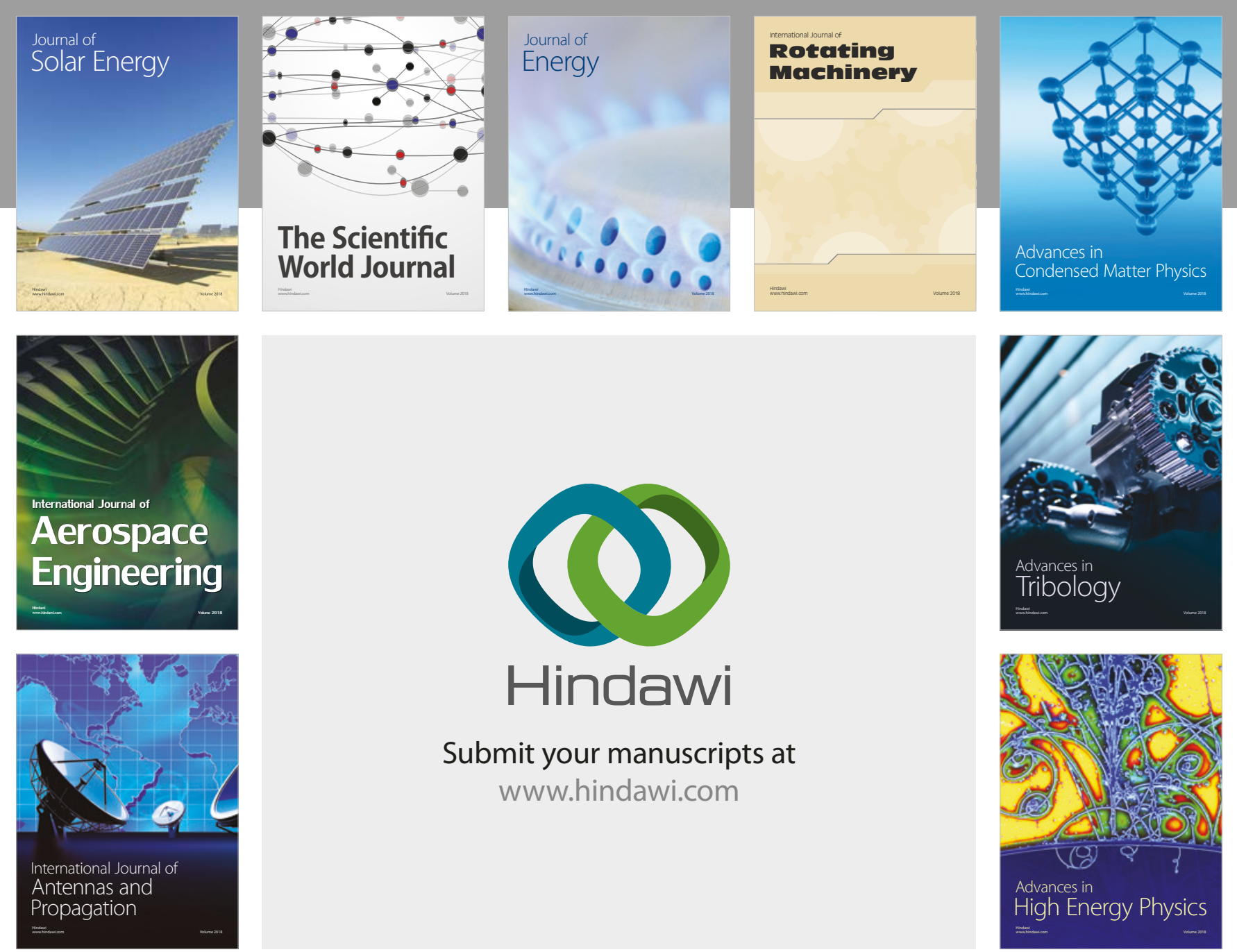

Submit your manuscripts at

www.hindawi.com
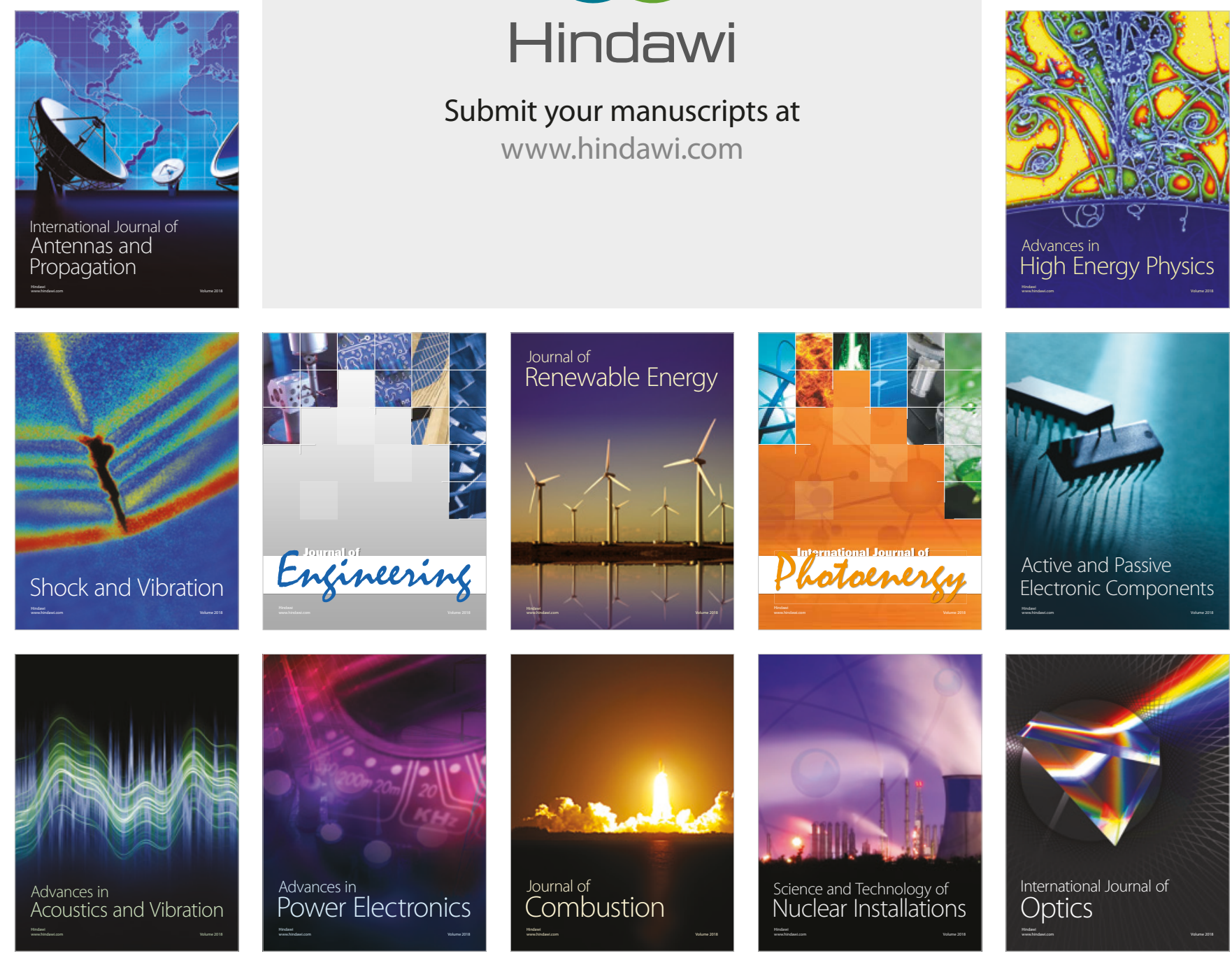